\section{CPS-108 A REVIEW OF INFLIXIMAB BIOSIMILAR TO BIOSIMILAR SWITCH: REMSIMA TO FLIXABI}

${ }^{1} \mathrm{R}$ O'neill*, 'S Singh, ${ }^{2} \mathrm{R}$ Luber. 'Guy's and St Thomas's NHS Foundation Trust, Pharmacy, London, UK; ${ }^{2}$ Guy's and St Thomas's NHS Foundation Trust, Gastroenterology, London, UK

10.1136/ejhpharm-2020-eahpconf.209

Background and importance In 2016, the local commissioning group and the gastroenterology directorate at a large acute teaching hospital switched all patients with inflammatory bowel disease (IBD) from the infliximab originator Remicade to the biosimilar Remsima. The success of this switch along with the emergence of more infliximab biosimilars with a license was an incentive for a biosimilar to biosimilar switch to be considered.

Aim and objectives

- The aim of this work was to assess the impact of a biosimilar to biosimilar switch in a large IBD unit.

- All IBD patients to switch from biosimilar Remsima to biosimilar Flixabi by August 2019.

- To obtain feedback from patients on the switch process using a patient survey.

- To assess the safety of the switch and to record if any adverse effects were experienced.

Material and methods A letter explaining the switch along with a frequently asked question document was sent to each patient prescribed Remsima for the treatment of IBD. Data were collected for each patient included: current infliximab dose $(\mathrm{mg} / \mathrm{kg})$, frequency of infusions (Q), patient weight $(\mathrm{kg})$, calculated dose $(\mathrm{mg})$, number of $100 \mathrm{mg}$ vials per dose, cost per dose per patient for Remsima and Flixabi, predicted saving and whether this was the patients first or second switch.

Results

- All IBD patients $(100 \%, \mathrm{n}=227)$ switched from biosimilar Remsima to biosimilar Flixabi.

- To date, $5.4 \%(n=2)$ of patients have reported adverse events through the survey.

- A total of $86 \%(n=32)$ of patients would still like to be informed in writing about similar switches in the future.

Conclusion and relevance The objective to switch IBD patients to Flixabi was achieved ahead of time and without any resistance from patients. Overall, the switch was well received, patients were satisfied with the process and 99.2\% of patients did not report any adverse events. The two reports of adverse effects were attributable to changes in the rate of administration rather than the drug. This study is ongoing and aims to address the concerns of multiple switches on immunogenicity and drug resistance by checking trough drug levels, antibodies, disease scores and $\mathrm{C}$ reactive protein pre and post switch. The data collected to date anecdotally showed that there was no negative clinical impact of multiple switches.

\section{REFERENCES AND/OR ACKNOWLEDGEMENTS}

No conflict of interest.

\section{CPS-109 ANALYSIS OF CHANGES IN DISEASE MODIFYING TREATMENT IN THE MANAGEMENT OF PATIENTS WITH MULTIPLE SCLEROSIS}

A Arancón Pardo*, C Sobrino Jiménez, E Rodríguez Martín, C Bilbao Gómez-Martino, E Villamañán Bueno, I Jiménez-Nácher, F Moreno Ramos, MÁ González Fernández, M Moreno Palomino, M García-Trevijano, A Herrero Ambrosio. Hospital Universitario La Paz, Pharmacy Department, Madrid, Spain

\subsection{6/ejhpharm-2020-eahpconf.210}

Background and importance Currently, several disease modifying drugs are approved for multiple sclerosis (MS). IFN $\beta-1 b$, IFN $\beta-1 \mathrm{a}$, pegIFN $\beta-1 \mathrm{a}$, glatiramer acetate, teriflunomide and dimethylfumarate are indicated for firstline therapy. Secondline treatment includes natalizumab, fingolimod, alemtuzumab, cladribine and ocrelizumab. When disease progresses, modifications between firstline drugs or switch to a secondline drug are proposed. It is essential to know their efficacy and security profiles in order to decide which is the best option for each patient.

Aim and objectives The main aim was to assess the reasons for changes in disease modifying drugs in MS patients in routine clinical practice.

Material and methods We included patients with MS who changed their treatment between 23 May 2018 and 26 March 2019. The collected data were duration of initial therapy, disease modifying drugs before and after the modification and reasons for treatment modification.

Results Forty-two patients had treatment modification during the study period, 26 (62\%) were women and mean age was 47 (SD 9.3) years. Twenty-four patients (57\%) had received one previous treatment, $10(24 \%)$ two previous treatments and $8(19 \%)$ three or more previous treatments. Median duration of previous treatment was 44 months (range 3-282). Previous treatment was a firstline drug in 34 patients $(81 \%)$ and modified treatment was a firstline drug in 24 (57\%). The main drugs used before the modification were IFN $\beta-1 \mathrm{a}(21 \%)$ and teriflunomide $(21 \%)$, and after the modification dimethylfumarate $(38 \%)$ and natalizumab (24\%). The reasons for treatment change were suboptimal response (24 patients; 57\%), treatment intolerance (12 patients; 29\%) and JC virus activation with progressive multifocal leucoencephalopathy risk (6 patients; 14\%). Among patients with suboptimal response to treatment, $12(50 \%)$ were treated with IFN and 8 (33\%) with teriflunomide or dimethylfumarate. Most remarkable reasons for treatment intolerance were IFN related flu-like symptoms.

Conclusion and relevance

- Suboptimal response was the main reason for change in disease modifying treatment in MS patients in routine clinical practice. We must consider that these patients have a high relapse risk and accumulate their impairment.

- Most patients were treated with firstline drugs before and after the modification. Secondline drugs are more effective but, due to the higher risk of adverse events, are restricted to patients who cannot receive any firstline drug.

\section{REFERENCES AND/OR ACKNOWLEDGEMENTS}

No conflict of interest. 